\title{
Cultural Competence: Developing and Assessing Multicultural Proficiency for Teachers and School Personnel in Hawaii
}

\author{
Caryl H. Hitchcock \\ University of Hawaii, Manoa \\ Mary Anne Prater \\ Brigham Young University, prater@byu.edu \\ Chuan Chang \\ University of Hawaii, Manoa
}

Follow this and additional works at: https://scholarsarchive.byu.edu/facpub

Part of the Teacher Education and Professional Development Commons

\section{Original Publication Citation \\ Hitchcock, Caryl H.; Prater, Mary Anne; and Chang, Chuan (2009) "Cultural Competence: Developing and Assessing Multicultural Proficiency for Teachers and School Personnel in Hawaii," Multicultural Learning and Teaching: Vol. 4: Iss. 2, Article 2.}

\section{BYU ScholarsArchive Citation}

Hitchcock, Caryl H.; Prater, Mary Anne; and Chang, Chuan, "Cultural Competence: Developing and Assessing Multicultural Proficiency for Teachers and School Personnel in Hawaii" (2009). Faculty Publications. 2066.

https://scholarsarchive.byu.edu/facpub/2066

This Peer-Reviewed Article is brought to you for free and open access by BYU ScholarsArchive. It has been accepted for inclusion in Faculty Publications by an authorized administrator of BYU ScholarsArchive. For more information, please contact ellen_amatangelo@byu.edu. 


\section{Multicultural Learning and Teaching}

$\begin{array}{lll}\text { Volume 4, Issue } 2 & 2009 & \text { Article } 2\end{array}$

\section{Cultural Competence: Developing and Assessing Multicultural Proficiency for Teachers and School Personnel in Hawaii}

Caryl H. Hitchcock, University of Hawaii at Manoa

Mary Anne Prater, Brigham Young University

Chuan Chang, University of Hawaii at Manoa

\section{Recommended Citation:}

Hitchcock, Caryl H.; Prater, Mary Anne; and Chang, Chuan (2009) "Cultural Competence: Developing and Assessing Multicultural Proficiency for Teachers and School Personnel in Hawaii," Multicultural Learning and Teaching: Vol. 4: Iss. 2, Article 2.

DOI: $10.2202 / 2161-2412.1049$ 
Multicultural Learning and Teaching

(2009), 4 (2), 1-24

\title{
Cultural Competence: Developing and Assessing Multicultural Proficiency for Teachers and School Personnel in Hawaii
}

\author{
Caryl H. Hitchcock, Mary Anne Prater, and Chuan Chang
}

\begin{abstract}
Teachers were recruited from the mainland of the United States to work in rural areas in the State of Hawaii to meet the high demand for personnel. But often there is a mismatch between the culture of the island residents and that of the new teachers. To alleviate this mismatch, a workshop was developed to promote multicultural proficiency of school personnel focusing on Asian/Pacific cultures. One bundred teachers, administrators and staff (including custodians and cafeteria workers) from four rural elementary schools participated in a three hour workshop. The workshop consisted of three activities: (a) self-awareness, (b) awareness of Asian/Pacific Island cultures, and (c) instructional strategies and resources to support culturally diverse students. A mixed repeated measures design was used to make comparisons between the workshop participants' responses on pre/post administrations of the Multicultural Assessment of Proficiency (MAP) scale, a questionnaire designed and developed to measure the effects of the workshop. Results indicated that all participants improved significantly and that three factors accounted for the majority of the variance: knowledge of strategies and resources, awareness of self/ others (beliefs), and willingness to take future action. Limitations, suggestions for future research, and implications for practice are discussed.
\end{abstract}

Key Terms: Multicultural Proficiency, Teacher Education, Cultural Competence, Professional Development, Multicultural Assessment

Diversity is positively changing the nature of our nation's classrooms. As schools are being populated with more students from diverse cultures, teachers are expected to be knowledgeable about and competent in teaching strategies to meet a variety of learning styles. The National Education Association (2000) reported the following facts about America's schools: (a) although one-third of students represent culturally and linguistically diverse (CLD) groups, only 13\% of teachers are from these groups; (b) $42 \%$ of public schools have no CLD teachers; and (c) projections for the future indicate that students from CLD groups will grow to $41 \%$, while the percentage of CLD teachers may shrink to $5 \%$. In fact, the percentage of racial/ethnic minority students enrolled in America's public schools increased from 31\% in 1986 to $43 \%$ in 2006 (NCES, 2007). These statistics demonstrate the need to not only prepare more teachers from CLD cultures, but also to educate current classroom teachers to become knowledgeable about and sensitive to the needs of students from CLD groups.

Culture impacts the learning process and social adjustment of our children, and providing developmentally and culturally appropriate practice (DCAP) is at the core of the teaching profession (Robles de Melendez \& Beck, 2007). Multicultural education has become a critical component for school personnel preparation and professional development, and such preparation should include an understanding of a variety of cultures (NCCTQ, 2007). The need for training in multicultural competency in teacher preparation programs is well-documented (e.g., Dieker, Voltz, \& Epanchin, 2002; Prater, Wilder, \& Dyches, 2008; Trent, Kea, \& Oh, 2008). Although several professional development workshops have been created for such training, we were unable to identify any that specifically addressed the competencies required of school personnel working with students from Asian/Pacific cultures. Thus, a workshop and questionnaire were developed to promote and measure teachers' multicultural proficiency with students from a variety of Asian/Pacific cultures. 


\section{Defining Culture}

Culture plays a large role in what and how we learn (Au, 2006; Tharp, Estrada, Dalton, \& Yamauchi, 2000; Vygotsky, 1978). Over time, the concept of culture has developed from a narrow definition, focusing on ethnicity or race, to one that is much broader (Kleinman, 1996). This study adopts the currently accepted broader definition of culture, which states that culture is the shared learned meanings and behavior derived from living within a particular life activity context. It includes external factors: artifacts, roles, activity contexts, institutions; and internal factors: attitudes, meanings, cognitive styles, consciousness patterns (Marsella \& Yamada, 1999). In this definition, culture is pervasive and is the fabric of our lives. The definition includes 10 cultural identifiers: race, ethnicity, religion, age, gender, geographic region, national origin, socioeconomic status, marital status or sexual orientation, and role orientation (Katz, 1995).

Hawaii's history of immigration has created an environment where teachers have experienced multicultural classrooms for many years, more so than their colleagues on the mainland. Hawaii's classrooms are a kaleidoscope of ethno cultural groups (Hawaii Department of Education, 2000). A teacher in Hawaii may have students from at least seven different ethnic groups and languages, for example, Japanese, Filipino, Samoan, Tongan, Hmong, Vietnamese, and Marshalese (Sileo \& Prater, 1998). Many teachers face a myriad of challenges when teaching students from a wide variety of language and cultural groups. For example, they must discover ways to include everyone, to instill a sense of appreciation and respect for differences, and to assist students to discover the commonalties that make us part of a global culture. There may be many languages and/or dialects for the teacher to learn, as well as a variety of cultural beliefs (Artiles \& ZamoraDuran, 1997; Lynch \& Hanson, 2004). Teachers must learn how to implement different instructional methods to meet a variety of learning styles (e.g., individual vs. collaborative) as well as understanding diverse family arrangements (Tharp et al., 2000).

\section{Competencies for Teachers}

One of the priorities of the No Child Left Behind Act of 2002 was that schools increase the quality of their teaching personnel, especially difficult in high poverty, low performing, and hard-tostaff schools. Teachers need preparation or ongoing support to handle the tremendous challenges and learning environments presented by at-risk schools (NCCTQ, 2007). One of the goals of this workshop was to provide professional training that focused on learning, developing, and sharing strategies for effective teaching with culturally and linguistically diverse students. Fitzgerald, Mullavey-O'Byrne, Clemson, and Williamson (1996) proposed the theory that cultural competency develops along a 6-point continuum including the following stages from negative to positive: cultural destructiveness (e.g., slavery of African Americans); cultural incapacity (agencies may support oppression through acceptance of stereotypes or enforcement of discriminatory policies); cultural blindness (implies that color and race doesn't make a difference, we are all the same); precompetence (hiring minority staff, implementing multicultural training); cultural competence (agencies characterized by acceptance and respect for differences); and cultural proficiency (conducting research, developing new therapeutic and educational approaches based on culture, using cultural specialists to provide services).

The challenge to all teachers, those new to the classroom and those with many years of experience, is to examine their beliefs and practices, their instructional methodologies and strategies, as well as to develop multicultural competencies. However, a review of the literature on the efficacy 
of multicultural education programs for both general and special education teachers found that little research had been conducted, noting a narrow focus and limited use of research designs (WebbJohnson, Artiles, Trent, Jackson, \& Velox, 1998). The eight studies in Webb-Johnson et al.'s review generally employed surveys and questionnaires without open-ended questions; and those that did employ qualitative methods lacked elements that increased trustworthiness (i.e., triangulation, prolonged engagement, and multiple measures). Given the need for teachers to become knowledgeable of their students' experiences and learning styles, the Council for Exceptional Children (CEC) has outlined teacher competencies required in their professional standards (CEC, 2003). In terms of cultural competence, they have documented the necessity for (a) awareness of self, (b) knowledge of other cultures/languages, and (c) skills (identifying strategies, and accurate communication). These competencies have been supported by many of the leading authors in the multicultural education literature, not only for teachers but also for other service providers such as counselors and clinical therapists (Lynch \& Hanson, 2004; Pedersen, 1999).

Purpose

The purpose of this study was to evaluate the effects of a multicultural workshop with groups of elementary school personnel using the Multicultural Assessment of Proficiency (MAP) questionnaire. The dependent variable (the multicultural proficiency of teachers) included measures of knowledge, attitude, and action orientation on multicultural issues on a pre- and post-workshop questionnaire. The research questions were: (a) Would the MAP questionnaire ratings increase from pre- to post-workshop; (b) Would the workshop activities be an effective method to develop change and proficiency; and (c) Would the attendees be able to list resources and strategies that could be used in the classroom? The hypothesis was that the ratings and responses on the postworkshop survey would be higher than those on the pre-workshop survey.

\section{Method}

\section{Developing the Workshop}

Lynch and Hanson's $(1998,2004)$ guide to developing cross-cultural competence had a major influence on the development of the workshop. The activities were based on their suggestions for self-exploration and the information they provided on values and beliefs of people from a variety of diverse cultures found in Hawaii. Workshop participants were assigned passages to read and discuss from chapters in their book on Asian/Pacific cultures. The process of developing cultural competence, that is, the three activities of the workshop (understanding our own culture, understanding other cultures, and knowledge of strategies/resources to teach CLD students), had been suggested in several studies and was adapted to meet the needs of this workshop (Gay, 1993; Montecinos, 1994; Washburn, 1994).

The goal of the workshop was to increase teacher's awareness, knowledge, and action orientation on multicultural issues. Specific activities were designed to (a) make teacher's aware of their own cultural values and beliefs, as well as how these might affect teaching styles, (b) help teacher's develop knowledge of and sensitivity to issues confronting their students from diverse backgrounds, and (c) provide teachers with effective skills and strategies for instruction of students in multicultural classrooms, as well as to develop examples of lesson plans that were both 
multicultural and standards-based. Workshop materials may be obtained by contacting the first author.

Developing the Questionnaire: The Multicultural Assessment of Proficiency (MAP)

The Multicultural Assessment of Proficiency (MAP) was developed to measure the effectiveness of the workshop in increasing multicultural proficiency in three areas: (a) knowledge, (b) awareness, and (c) action orientation (i.e., willingness to implement culturally appropriate lesson plans, teaching strategies, and use resources). The MAP consisted of 20 statements that the teachers rated on a 6-point Likert scale, 2 statements for each of the three workshop activities for each area (i.e., awareness, knowledge, and action orientation), plus 2 additional statements relating to awareness/beliefs. The questionnaire also contained 7 open-ended questions that requested participants to list strategies and resources that they would use. A copy of the MAP is provided in the Appendix.

\section{Procedures}

The workshop and survey instrument were created by the first author as demonstration of multicultural competence in a doctoral program. The Hawaii State Department of Education then invited the first author to implement these materials as professional development training for the employees at four elementary schools. A workshop for each school was scheduled for a 3 hour period in the morning on a day chosen by the school during the first semester. All school personnel were required to attend. Upon arrival, each participant signed in, received the one page demographic questionnaire and the three page Multicultural Assessment of Proficiency (MAP) survey to complete, as well as a folder containing their workshop handouts (described below). Each survey was coded to provide anonymity. Other materials used to conduct the workshop (such as a computer, LCD projector and screen, resource books, and writing materials) were available in the room. Participants were grouped in teams of four seated at tables, as each of the workshop activities required collaboration. When the 3 hour workshop was completed, the participants were again asked to complete the MAP survey. The data from the surveys were collected and entered into an Excel spreadsheet for analysis.

\section{Materials}

The materials for the workshop included PowerPoint slides, handouts, resource book chapters and a short video. Each is described below.

PowerPoint slides. Twenty-one slides were created to guide the participants through the activities of the workshop. The first six slides presented the goals of the workshop, background on issues in multicultural education, and focus questions, such as "What initial steps can a teacher take to become culturally sensitive, responsive, and proficient?" Two to five slides outlined information and instructions for each of the activities and included slides on the broad definition of culture and Whitney's (1987) comparison table of mainland vs. local culture. Three final slides concluded the workshop with a philosophy statement and instructions for completing the MAP survey.

Handouts. Handouts from the PowerPoint presentation were printed and placed in the participants' workshop folders to facilitate note-taking. In addition, four 1 page handouts included the following information: (a) definition of culture; (b) Geertz's theoretical model of thin and thick 
description; (c) the concept of the assimilation, acculturation, and separatism continuum (Katz, 1995); and (d) James Banks' (2001) four-stage model of multicultural education.

Resource book chapters. Multiple copies of Lynch and Hanson's (1998) book were purchased for the workshop and participants were assigned short readings. A Cultural Journey (p 87-89) was assigned as reading for Activity 1. Chapters on culture from Asian ( $\mathrm{p}$ 345-350), Pilipino ( $\mathrm{p}$ 401-405), Anglo-European (p 121-123), and Native Hawaiian and Samoan (p 436-437) ethnicities were provided as readings for Activity 2 (although these readings could be varied to adapt the workshop for other school demographics such as Latino, African or Native American). The chapters covered contrasting beliefs, values, practices, cultural courtesies and customs, nonverbal behavior, communication and conversation, private homes, family, and gift giving customs. Instructions were to choose readings about a cultural group that was most different from one's own.

Video. A short video segment from an Instructional Conversation (Adger et al., 1998) was played to illustrate the impact of culture on a mathematics lesson. The video showed how the concept of number varies widely across cultures as well as the use of language to describe number concepts.

Writing materials. Writing materials provided to the participants included index cards, white poster paper, and colored markers.

Independent V ariable: Workshop on Multicultural Issues in Education

Time. The workshop was completed in one 3-hour session. The presenter set the stage by highlighting current issues in multicultural education, the goals of the workshop, and focus questions. Each of the three activities took approximately 45 minutes to complete. A 10 -minute break was scheduled between the second and third activities.

Activity 1. The goal of the first activity was to help teachers discover their own cultural values and beliefs and the impact these might have on others. The directions to the teachers and school personnel were described in PowerPoint slides and focused on the participants identifying their own cultural values (i.e., origins, heritage, language, history and development, family) and drawing a symbol to represent themselves or an enduring value. Participants were given approximately 10 minutes to complete this activity and share results with their group. The definition of culture (referring to the handout of cultural identifiers) was reviewed, as well as similarities and differences in cultural values (e.g., concept of and use of time). Participants were asked to identify four cultural values that they would bring to the classroom.

Activity 2. The goal of the second activity was to help teachers become knowledgeable and sensitive to issues of concern to students from diverse cultural backgrounds. Teachers were asked to choose a cultural group most different from their own and brainstorm what they knew about that group. With the handouts they were asked to construct a table that compared and contrasted their values and beliefs with those of the other culture. Choices for study of others' ethnicity included: Native Hawaiian/Samoan, Asian, Filipino, and Anglo-European. Points of comparison included communication styles, verbal and nonverbal language, ideology, and practices. A sample table from Whitney (1987) was provided.

Activity 3. The goal of the third activity was to provide teachers with examples of resources and effective strategies for instruction of culturally diverse students. The school personnel were 
divided into teams of 4 participants and presented PowerPoint slides of strategies and resource materials, as well as a concept map of the resources and strategies to aid retention. A 5-minute video example of a multicultural mathematics lesson was shown (Adger et al., 1998). The teams brainstormed a lesson plan appropriate for students from their cultural group, wrote it on poster paper, and shared it with the large group. Each team included at least one teacher who was familiar with the process of writing a standards-based lesson plan.

\section{Dependent Variable: The MAP}

The MAP questionnaire was administered at the beginning of the workshop and again at the end. Participants were given 10-15 minutes to complete it each time. Small "reward" boxes containing teacher supplies such as Post-it Notes, pencils, erasers, sharpeners, and rulers were given to each participant who turned in both pre- and post-questionnaires at the end of the workshop.

\section{Participants and Setting}

One hundred school personnel from four elementary schools participated in the workshops. School personnel included teachers, administrators, educational assistants as well as ancillary staff such as custodians and cafeteria helpers. The workshop was conducted in a school cafeteria, conference room, library, or classroom equipped with desks, chairs, a VCR, TV monitor, LCD projector, and screen. The study was conducted during the first quarter of the school year.

Demographic information on each participant was collected and included the following: date and place of birth, gender, ethnicity, current teaching or school position, number of years lived in Hawaii, degree program and major, first language, number and list of languages spoken fluently, and whether the participant had taken a course in multicultural education. This information was requested on a separate cover page of the evaluation instrument. The workshop participants were arranged in groups of 4 participants with each group containing at least one teacher who was able to facilitate writing a lesson plan.

Results of the demographic data were as follows (see Table 1). Over half of the participants were teachers $(n=52)$, the majority of whom were Hawaiian or Part Hawaiian, female, born in Hawaii, and residents of Hawaii for more than 30 years. The majority of school personnel were likely to be $40-50$ years old. New teachers were more likely to be younger Caucasian females, who had lived in Hawaii for fewer than 5 years. Twenty-four participants had advanced degrees (MA or higher) and 42 had previously taken a course in multicultural education. Educational assistants $(n=$ 20) made up the next largest group. All of the educational assistants were females from the community and reflected the demographics of the students, a majority being Hawaiian or Part Hawaiian (see Table 2). None held a higher education qualification above an Associate's Degree or had taken a course in multicultural education. The remaining personnel included administrators, counselors, school support and classified staff such as custodians, cafeteria helpers, or school secretaries.

\section{Quantitative Analysis}

Likert scale ratings on the pre- and post-surveys were analyzed with a paired-samples $t$ test. An exploratory factor analysis was conducted to examine the factorial structure of the MAP survey. After the three dimensions (multicultural knowledge, awareness, and action orientation) were 
successfully extracted, a multivariate repeated measures analysis was performed to determine the effect of the workshop intervention on the three dimensions. The following items from the demographic survey were examined: age, gender, ethnicity, place of birth, years living in Hawaii, language (English as first language or bilingual), position at school (teacher or other), current degree held, and whether the participant had taken a course in multicultural education.

\section{Qualitative Analysis.}

A content analysis including a frequency count of teacher responses (i.e., similar phrases) on the seven open-ended questions (\# 1,2, 4, 5, 6, 17, and 18) was performed. The analysis was conducted to determine increases in knowledge and to develop categories of multicultural competence. Participants' responses on these items should reflect their development, history, background, and culture. Responses were examined to discover participants' progress toward multicultural competency and to determine which of the workshop activities were most useful in facilitating this development.

\section{Results}

Ninety-five of the 100 participants returned their completed pre- and post-questionnaires. Four of 95 were not complete, yielding a final sample of 91 participants. Therefore, a return rate of usable questionnaires equaled $91 \%$. Results were analyzed using a paired-samples $t$ test. This analysis revealed a significant difference in each MAP item score before and after the workshop. The sample means are displayed in Table 3, which shows that mean scores were significantly higher in the posttest than in the pretest for all items. The observed differences between these mean scores range from 0.19 to 1.14. The effect sizes were computed as Cohen's $d$ and range from 0.25 to 1.14. According to Cohen's guidelines, $d=0.50$ and $d=0.80$ represent a medium and large effect, respectively. As shown in Table 3, seven MAP items have medium to large effects. The largest effect is observed on Item 6 ("I am knowledgeable about resources that I might use in a multicultural classroom"), $t(80)=10.25, p<.001$. The mean scores were significantly higher in posttest $(M=$ $4.99, S D=0.81)$ than in pretest $(M=3.85, S D=1.07)$. The observed difference between the mean scores was 1.14, and the 95\% confidence interval for the difference between means extended from 0.92 to 1.36 . The effect size was computed as $d=1.14$, which represents a large effect.

In order to reduce the redundancy and number of dependent variables in these data, an exploratory factor analysis was carried out for the MAP pre-questionnaire data based on 79 participants who had completed responses to all of the $20 \mathrm{MAP}$ items. Three common factors were identified, on which all of the 20 items yielded salient loadings (larger than 0.35). Combined, Factors 1 to 3 accounted for $74 \%$ of the total variance. Factor scores were generated by averaging the scores on the salient items and used in multivariate analyses.

The first factor was named Action Orientation and includes 7 items (Items 14-20) addressing the willingness to .... For example, "I am willing to use instructional strategies to promote respect, understanding, and a sense of belonging for all." The second factor, Awareness, includes 10 items (Items 1-3 and 7-13) addressing the awareness and beliefs related to culture. For example, "I believe that culture is a major force in shaping my behaviors, values, and institutions (e.g., families)." The third factor was named Knowledge and includes 3 items (Items 4-6) addressing competencies. For example, "I am knowledgeable about instructional strategies for a multicultural classroom." Scale reliability was assessed by calculating Cronbach coefficient alpha. Reliability estimates were .93, .94, 
and .81 for the action orientation, awareness, and knowledge scales, respectively. The questionnaire items associated with each factor along with the coefficient alpha reliability estimates were reported in Table 4.

Subsequent repeated measures MANOVA revealed an overall significant increase in participants' responses on the MAP scales over time, $F(3,69)=31.3, p<.001$. Univariate tests further indicated that the changes in participants' responses were significant on each of the three MAP factors, $F(1,71)=17.5, p<.001$ for Action Orientation, $F(1,71)=25.0, p<.001$ for Awareness, and $F(1,71)=89.8, p<.001$ for Knowledge. The effect size for the overall change from pre to post on the MAP was 0.58, and it ranged from medium on Knowledge (0.57) to small on Awareness (0.26) and Action Orientation (0.20). Potential impacts of demographic variations were investigated using multiple two-way MANOVAs. Variables examined included the following: age, gender, ethnicity, place of birth, years living in Hawaii, language (English as first language or bilingual), position at school (teacher or other), current degree held, and whether the participant had taken a course in multicultural education. Significant between-subjects effects were found on the data by position held (i.e., teacher vs. other school personnel, such as an educational assistant), $F$ ( 3 , $69)=3.8, p<.05$, and level of education (i.e., a higher education degree vs. a high school or associate's degree), $F(3,69)=3.9, p<.05$. Univariate tests further showed that the differences between participants with teaching positions and those who held other or educational assistant positions became significant on the Awareness, $F(1,71)=5.3, p<.05$, and Knowledge, $F(1,71)=$ $10.1, p<.01$, factors but not on the Action Orientation factor. The same pattern was observed with participants who held higher degrees versus those who did not, $F(1,71)=6.9, p<.05$ on the Awareness factor and $F(1,71)=9.7, p<.01$ on Knowledge. No interaction effects between time and position and between time and education level were detected as both groups improved on the three pre to post measures. They did so from different starting points and improved similarly as illustrated in Figure 1. No significant effect was found on other potentially interesting demographic variables, such as place of birth, years in Hawaii, and bilingual status.

\section{Qualitative Analysis}

The frequency and variety of responses to the open-ended questions on the MAP survey supported the results of the quantitative analysis. That is, the greatest effect was on Factor 3, Knowledge. On the initial pre-workshop administration of the survey, the participants listed resources and strategies, but the resources were fewer and less varied. On the post-workshop survey, participants listed more and a greater variety of strategies and resources. New hypotheses remain to be generated and analyzed in this section; however, it was interesting to note the strong sense of Hawaiian values, use of Hawaiian language, and ability to list contrasting cultural perspectives. Syntheses of the results of the qualitative analysis are presented in Tables 5 and 6 . Workshop teams produced lesson plans on topics such as writing, math, art, and social studies that incorporated a variety of teaching strategies and resources that were sensitive to multicultural audiences.

\section{Discussion}

The overall quantitative and qualitative results indicate that the respondents' ratings on the MAP questionnaire improved following participation in the workshop. The activities of the workshop appeared successful in increasing multicultural competency, and most respondents demonstrated gains. It could be concluded that the workshop achieved its first goal of increasing proficiency with school personnel who work with culturally and linguistically diverse (CLD) 
students. The MAP questionnaire appeared to be a reliable and valid instrument to measure multicultural proficiency. The factorial structure was clean, and the reliability coefficients were high (ranging from .81 to .94) on the preliminary factor analysis of the questionnaire. A majority of the variance $(74 \%)$ was explained by the presence of the investigators' three proposed factors: Action Orientation, Awareness, and Knowledge.

Among the three factors identified by the factor analysis, the largest effect size was for Factor 3: knowledge of strategies and resources to use in a multicultural classroom. This result was interesting because it demonstrated that the workshop was not only effective in increasing knowledge of strategies and resources but also effective to a lesser degree in increasing awareness (Factor 2) and willingness to act (Factor 1). Surprisingly, none of the demographic factors, such as age, gender, ethnicity, or years living in Hawaii had a significant effect on the ratings outcome. One might expect new teachers from the mainland of the United States (or elsewhere) to have responded differently than long-time Hawaii residents. These results could be explained by the small numbers of mainland teachers in the group, as well as by the high number of teachers and school personnel who identified themselves as Native Hawaiians, which contrasted with the picture presented by the National Education Association (2000) at the beginning of the article. In these schools there was greater similarity between the teachers and students in terms of culture and language. However, the level of education and the position held at the school appeared to make a difference. After participating in the activities of the workshop, all participants improved on the ratings pre- to postworkshop, and there was no interaction effect. Although they started from different points on the rating scale, both improved. It seemed that all school personnel, not only teachers, benefited from the workshop. Finally, workshop participants were able to state resources and strategies that they could use to help them in their work with culturally and linguistically diverse students. They also expressed an awareness of the issues and willingness to engage in action in the future.

\section{Limitations}

Due to threats to internal validity, one would expect pretest posttest changes, but these changes do not indicate causality. Ninety-one participants were not enough to perform a reliable factor analysis, and the use of twenty pair-samples t-test increase the overall Type I error rate; therefore, these results should be interpreted at an alpha level of .05 divided by twenty(the number of total of .0025 alpha Level)(Sapp, 2006). Due to threats to internal validity, these results do not imply causality. For example, this research design suffered from several threats to internal validity such as history, maturation, and pretest sensitization. In addition, there were not enough participants to perform a reliable factor analysis, and the use of twenty-pair sample t-tests increased the overall Type I error rate; therefore, these results should be interpreted with caution (Sapp, 2006).

Time was the greatest limitation of this study. It would be unrealistic to think that a lifetime of cultural values and beliefs could be changed and competencies acquired in a 3-hour workshop (Goldenberg \& Gallimore, 1991). A practice effect with the use of the same questionnaire both before and after the workshop is another limitation of this repeated measures design. However, the open-ended questions to measure increases in teacher competencies were added to partially counteract this effect. Factors relating to the questionnaire and its construction may have affected the measures. Unclear wording of responses and questions was examined and found not to be a significant factor, given the high reliability of the questionnaire items. The item analysis was included to examine the relationship of the questions to the constructs being measured (e.g., knowledge, awareness, action orientation). Cognitive dissonance or social desirability may have affected the 
questionnaire responses. The use of quantitative analyses has limitations. There might have been a few teachers with excellent multicultural skills within the group, and this was supported by the responses to the open-ended survey questions. The data and rich description of the qualitative analysis also highlighted the encompassing, constantly fluid, and changing nature of cultural diversity as proposed by Lynch and Hanson (1998, 2004).

A follow up interview or focus group could be conducted to examine the long-term effect of the workshop, as well as to include a qualitative measure of the workshop's efficacy and social validity. Mentoring or other professional development support could be provided throughout the school year. There may have been bias in group composition (i.e., $42 \%$ of the school personnel reported having taken a class in multicultural education). However, as all participants' ratings improved, the workshop appeared to benefit all who attended. An analysis was included to identify the significant factors on the measures of multicultural competence in the workshop. Three factors were identified as significant, with the most significant effect on knowledge of strategies and resources. These results suggest that all three activities were important to conduct; however, our study did not examine the order of activities and whether this was an important variable.

\section{Suggestions for Future Research and Implications for Practice}

A workshop designed to promote multicultural proficiency conducted near the beginning of the school year appeared to produce significant results. The workshop benefited all school personnel, not only teachers. Future research might include a follow-up interview with school personnel to determine whether they had used strategies or resources from the workshop. A qualitative analysis employing content and textual analysis could be used to compare these responses with the responses given on the questionnaire immediately after the workshop. Extending the activities over a longer time and integrating them with a professional development program (with follow-up mentoring and support) would also be suggested areas for future research.

\section{Conclusion}

This study found that the post-workshop measures of knowledge, attitude, and action orientation on multicultural issues increased significantly on the evaluation instrument (the MAP). This finding suggests that the three activities of the workshop provided a useful way to increase cultural sensitivity and provide resources and teaching strategies. A surprising finding was that teachers new to Hawaii had ratings not significantly different from long-time residents. An interesting discovery was the high measures reported on the pre-workshop survey, which suggested that school personnel were previously sensitive to the issues and challenges and knew some strategies and resources. Another interesting finding was the integrity of the evaluation instrument with its high level of internal validity, which suggests that it may be a good tool to measure multicultural proficiency and worthy of further study.

\section{References}

Adger, C., Childs-Bowen, D., Hill, H., Lachat, M. A., Pellicer, L. O., Peyton, J. K., Corporation, R. R., Rodriguez, B. M., Stinette, L. J., \& Williams, B. (1998). Educating linguistically and culturally diverse students. Alexandria, VA: Association for Supervision and Curriculum Development. 
Artiles, A. J., \& Zamora-Duran, G. (Eds.). (1997). Reducing disproportionate representation of culturally diverse students in special and gifted education. Reston, VA: Council for Exceptional Children.

$\mathrm{Au}, \mathrm{K} . \mathrm{H}$. (2006). Multicultural issues and literacy achievement. Mahwah, NJ: Erlbaum Associates.

Banks, J. A., \& Banks, C. A. M. (2001). Multicultural education: Issues and perspectives (4th ed.). Boston: Allyn \& Bacon.

Council for Exceptional Children. (2003). What every special educator must know: Ethics, standards, and guidelines for special educators (5th ed.). Retrieved June 10, 2008, from http://www.cec.sped.org/Content/NavigationMenu/

ProfessionalDevelopment/ProfessionalStandards/Red_book_5th_edition.pdf

Dieker, L., Volt D., \& Epanchin, B. (2002). Report of the Wingspread Conference: Preparing teachers to work with diverse learners. Teacher Education and Special Education, 25, 1-10.

Fitzgerald, M. H., Mullavey-O'Byrne, C., Clemson, L., \& Williamson, P. (1996). Enhancing cultural competency. Sydney: Transcultural Mental Health Center.

Gay, G. (1993). Ethnic minorities and educational equality. In J. A. Banks \& C. A. McGee Banks (Eds.), Multicultural education: Issues and perspectives (pp. 169-192). Boston, MA: Allyn \& Bacon.

Goldenberg, C., \& Gallimore, R. (1991). Changing teaching takes more than a one-shot workshop. Educational Leadership, 49, 69-72.

Hawaii Department of Education (2000). School Statistics, [internet]. State of Hawaii. Available: http://www.k12.hi.us [2000, September 1].

Hawaii Department of Education (2000). Professional Requirements, [internet]. State of Hawaii. Available: http://www.k12.hi.us [2000, September 1].

Katz, L. L. (1995). Respecting diversity in the classroom: Facilitator's guide. Bloomington, IN: Agency for Instructional Technology.

Kleinman, A. (1996). How is culture important for DSM-IV? In J. E. Mezzich \& A. Kleinman \& H. Fabrega \& D. L. Parron (Eds.), Culture and psychiatric diagnosis (pp. 15-25). Washington, DC: American Psychiatric Press.

Lynch, E. W., \& Hanson, M. J. (Eds.). (1998). Developing cross-cultural competence: A guide for working with families (2nd ed.). Baltimore, MD: Paul H. Brookes.

Lynch, E. W., \& Hanson, M. J. (Eds.). (2004). Developing cross-cultural competence: A guide for working with children and their families (3rd ed.). Baltimore, MD: Paul H. Brookes.

Marsella, A. J., \& Yamada, A. M. (1999). Culture and mental health: An introduction and overview of foundations, concepts, and issues. In I. Cuellar \& F. Paniagua (Eds.), The Handbook of Multicultural Mental Health: Assessment and Treatment of Diverse Populations (pp. 2-24). New York: Academic Press.

Montecinos, C. (1994). Teachers of color and multiculturalism. Equity and Excellence in Education, 27, $34-42$. 
National Center for Educational Statistics. (2007). Status and trends in the education of racial and ethnic minorities. Retrieved June 10, 2008: http://nces.ed.gov/pubs2007/minoritytrends/

National Education Association. (2000). Status of the American Public School Teacher 2000-2001. Retrieved October 16, 2008, from http://www.nea.org/edstats/images/status.pdf

NCCTQ Biennial Report. (2007). America's challenge: Effective teachers for at-risk schools and students. Retrieved June 12, 2008, from http:/ / www.ncctq.org/publications/NCCTQBiennialReport.pdf

Pedersen, P. (Ed.). (1999). Multiculturalism as a fourth force. Philadelphia, PA: Brunner/Mazel.

Prater, M. A., Wilder, L. K., \& Dyches, T. T. (2008). Shaping one traditional special educator preparation program toward more cultural competence. Teaching Education, 19, 137-151.

Robles de Melendez, W. J., \& Beck, V. (2007). Teaching young children in multicultural classrooms: Issues, concepts, and strategies (2nd ed.). Clifton Park, NY: Thomson Delmar Learning.

Sapp, M. (2006). Basic psychological measurement research designs, and statistics without math. Springfield, IL: Charles C. Thomas.

Sileo, T. W., \& Prater, M. A. (1998). Creating classroom environments that address the linguistic and cultural backgrounds of students with disabilities: An Asian Pacific American perspective. Remedial and Special Education, 19, 323-337.

Tharp, R. G., Estrada, P., Dalton, S. S., \& Yamauchi, L. A. (2000). Teaching transformed: Achieving excellence, fairness, inclusion, and harmony. Boulder, CO: Westview Press.

Trent, S. C., Kea, C. D., \& Oh, K. (2008). Preparing preservice educators for cultural diversity: How far have we come? Exceptional Children, 73, 328-350.

Vygotsky, L. S. (1978). Interaction between learning and development. In M. Cole \& V. John-Steiner \& S. Scribner \& E. Souberman (Eds.), Mind in society: The development of higher psychological processes (pp. 79-91). Cambridge, MA: Harvard University Press.

Washburn, D. E. (1994). Let's take a hard look at multicultural education. Multicultural Education, 2, $20-25$.

Webb-Johnson, G., Artiles, A. J., Trent, S. C., Jackson, C. W., \& Velox, A. (1998). The status of research on multicultural education in teacher education and special education: Problems, pitfalls, and promises. Remedial and Special Education, 19, 7-15.

Whitney, S. (1987). "I would always take care of my net": Self-esteem and the assumptive world of local youth. Journal of Community Education Association, 1, 7-13. 
Table 1

Demographics of multicultural workshop training participants $(N=100)$.

\begin{tabular}{|c|c|c|}
\hline Category & & Percent/Number \\
\hline \multirow{2}{*}{ Gender } & Male & 20 \\
\hline & Female & 80 \\
\hline \multirow{2}{*}{ Age } & Less than 35 years & $22\left(21^{*}\right)$ \\
\hline & More than 35 years & $78(74 *)$ \\
\hline \multirow{5}{*}{ Ethnicity } & Hawaiian/ Part HI & 49 \\
\hline & Caucasian & 27 \\
\hline & Filipino & 11 \\
\hline & Japanese & 8 \\
\hline & Other (Native Am., Hispanic, Pacific Islander) & 5 \\
\hline \multirow{3}{*}{ Place of Birth } & Hawaii & 70 \\
\hline & US Mainland & 26 \\
\hline & Other (Fiji, Philippines, Marshall Islands) & 4 \\
\hline \multirow{2}{*}{ Years in Hawaii } & Less than 5 years & 18 \\
\hline & More than 5 years & 82 \\
\hline \multirow{3}{*}{ School Position } & Teacher & 54 \\
\hline & Educational Assistant & 20 \\
\hline & Other (Classified or support) & 26 \\
\hline \multirow{3}{*}{ Degree Held } & $\mathrm{BA}$ & 44 \\
\hline & $\mathrm{MA}$ & 24 \\
\hline & Other (AA or HS) & 32 \\
\hline \multirow{2}{*}{ First Language } & English & 98 \\
\hline & Other & 2 \\
\hline \multirow[t]{2}{*}{ Bilingual } & $\begin{array}{l}\text { Yes (English, French, German, Hawaiian, Spanish, } \\
\text { Kiribati, Japanese) }\end{array}$ & 14 \\
\hline & No & 86 \\
\hline \multirow{2}{*}{$\begin{array}{l}\text { Previous Multicultural } \\
\text { Course }\end{array}$} & Yes & 42 \\
\hline & No & 58 \\
\hline
\end{tabular}

Note: ${ }^{*}$ missing data: 5 respondents did not provide birthdates 
Table 2

Student demographics by school

\begin{tabular}{lcccc}
\hline Variables & School 1 & School 2 & School 3 & School 4 \\
\hline Enrollment & 387 & 264 & 54 & 118 \\
Native Hawaiian & $84 \%$ & $68 \%$ & $79 \%$ & $87 \%$ \\
SPED & $10 \%$ & $15 \%$ & $11 \%$ & $24 \%$ \\
ELL & $3 \%$ & $5 \%$ & $4 \%$ & $0 \%$ \\
Free/Reduced Lunch & $64 \%$ & $75 \%$ & $87 \%$ & $75 \%$ \\
Math Proficient* & $15 \%$ & $5 \%$ & $11 \%$ & $17 \%$ \\
Reading Proficient* & $27 \%$ & $26 \%$ & $14 \%$ & $39 \%$ \\
\hline
\end{tabular}

Note. ${ }^{*}=$ HCPS II Reading \& Math 
Table 3

Mean Levels of MAP Item Scores Observed for Participants Before versus After Workshop, Paired Samples Design.

\begin{tabular}{|c|c|c|c|c|c|c|c|c|c|c|c|}
\hline \multirow{2}{*}{$\begin{array}{l}\text { MAP } \\
\text { Item \# }\end{array}$} & \multirow{2}{*}{$\begin{array}{c}\text { Mean } \\
\text { Pre } \\
\end{array}$} & \multirow[b]{2}{*}{ SD Pre } & \multirow{2}{*}{$\begin{array}{c}\text { Mean } \\
\text { Post } \\
\end{array}$} & \multirow[b]{2}{*}{ SD Post } & \multirow{2}{*}{$\begin{array}{c}\text { Mean } \\
\text { Diff. }\end{array}$} & \multirow{2}{*}{$\begin{array}{c}S D \\
\text { Diff. } \\
\end{array}$} & \multicolumn{2}{|c|}{$\begin{array}{l}95 \% \mathrm{Cl} \text { of the } \\
\text { Difference }\end{array}$} & \multirow[b]{2}{*}{$t$} & \multirow[b]{2}{*}{$d f$} & \multirow{2}{*}{$\begin{array}{c}\text { Cohen's } \\
d\end{array}$} \\
\hline & & & & & & & Lower & Upper & & & \\
\hline Pair 1 & 4.66 & .99 & 5.10 & .87 & .44 & .90 & .25 & .63 & $4.64 * * *$ & 87 & .50 \\
\hline Pair 2 & 4.98 & 1.03 & 5.31) & .75 & .34 & .90 & .15 & .53 & $3.52^{* *}$ & 88 & .37 \\
\hline Pair 3 & 4.89 & 1.00 & $5.21)$ & .74 & .32 & .85 & .15 & .50 & $3.62 * * *$ & 89 & .38 \\
\hline Pair 4 & 4.52 & .97 & 5.09 & .71 & .57 & .90 & .38 & .76 & $5.97 * * *$ & 89 & .63 \\
\hline Pair 5 & 3.99 & .92 & 4.95 & .79 & .97 & .95 & .76 & 1.17 & $9.52 * * *$ & 87 & 1.02 \\
\hline Pair 6 & 3.85 & 1.07 & 4.99 & .81 & 1.14 & 1.00 & .92 & 1.36 & $10.25^{* * *}$ & 80 & 1.14 \\
\hline Pair 7 & 4.97 & .94 & 5.38 & .71 & .41 & .79 & .25 & .578 & $4.93 * * *$ & 89 & .52 \\
\hline Pair 8 & 5.01 & .91 & 5.42 & .65 & .41 & .92 & .22 & .60 & $4.22 * * *$ & 90 & .44 \\
\hline Pair 9 & 5.03 & 1.03 & 5.43 & .69 & .39 & .81 & .22 & .56 & $4.49 * * *$ & 86 & .48 \\
\hline Pair 10 & 5.06 & 1.03 & 5.41 & .70 & .36 & .85 & .18 & .53 & $3.96 * * *$ & 89 & .42 \\
\hline Pair 11 & 5.08 & .99 & 5.47 & .66 & .40 & .86 & .22 & .57 & $4.42 * * *$ & 90 & .46 \\
\hline Pair 12 & 5.27 & .97 & 5.53 & .67 & .27 & .87 & .08 & .45 & $2.90 * *$ & 89 & .31 \\
\hline Pair 13 & 5.01 & 1.01 & 5.43 & .70 & .42 & .78 & .26 & .58 & $5.14 * * *$ & 90 & .54 \\
\hline Pair 14 & 4.73 & 1.159 & 5.16 & .96 & .42 & .82 & .25 & .59 & $4.88 * * *$ & 89 & .51 \\
\hline Pair 15 & 5.27 & .895 & 5.51 & .69 & .23 & .68 & .09 & .37 & $3.22 * *$ & 90 & .34 \\
\hline Pair 16 & 5.13 & .933 & 5.44 & .72 & .31 & .77 & .15 & .47 & $3.81 * * *$ & 90 & .40 \\
\hline Pair 17 & 5.30 & .897 & 5.49 & .69 & .19 & .77 & .03 & .35 & $2.35^{*}$ & 88 & .25 \\
\hline Pair 18 & 5.12 & .975 & 5.42 & .70 & .29 & .74 & .14 & .45 & $3.72 * * *$ & 88 & .39 \\
\hline Pair 19 & 5.08 & .969 & 5.45 & .73 & .37 & .80 & .21 & .54 & $4.47^{* * *}$ & 90 & .47 \\
\hline Pair 20 & 5.23 & .895 & 5.49 & .72 & .26 & .79 & .10 & .43 & $3.20 * *$ & 90 & .34 \\
\hline
\end{tabular}


Multicultural Learning and Teaching (2009), 4 (2), 1-24

Table 4

Factor-Based Scale Means, Standard Deviations, Intercorrelations, and Coefficient Alpha Reliability Estimates for the MAP Surveys $(N=79)$

\begin{tabular}{|c|c|c|c|c|c|c|}
\hline & \multirow[t]{2}{*}{ MAP Items } & \multicolumn{2}{|c|}{ Mean $(S D)$} & \multirow{2}{*}{$\begin{array}{c}\text { Factor } \\
1\end{array}$} & \multirow{2}{*}{$\begin{array}{c}\text { Factor } \\
2\end{array}$} & \multirow{2}{*}{$\begin{array}{c}\text { Factor } \\
3\end{array}$} \\
\hline & & Pretest & Posttest & & & \\
\hline Action Orientation & \# 14-20 & $5.2(.85)$ & $5.5(.66)$ & $(.93)$ & & \\
\hline Awareness (Beliefs) & \# 1-3 \& 7-13 & $5.0(.85)$ & $5.4(.60)$ & .78 & $(.94)$ & \\
\hline $\begin{array}{l}\text { Knowledge } \\
\text { (Strategies/Resources) }\end{array}$ & \# 4-6 & $4.1(.89)$ & $5.0(.67)$ & .54 & .63 & $(.81)$ \\
\hline
\end{tabular}

Note: Coefficient alpha reliability estimates appear on the diagonal. 
Table 5

Synthesis of Responses Listed to Open-Ended Questions on Values/Beliefs, Learning Styles, and Contrasts

1. I can identify behaviors and attitudes of my own that are unique to my culture.

List some values/beliefs that are important to you:

- Family (Ohana)

- Respect (Ho'ihi)

- Honesty (Kupono)

- Education

- Compassion

- Courage

- Working together

- Keeping promises (Ho'ohihi)
- Responsibility (Kuleana)

- Love/kindness (aloha)

- Integrity (Pa'a pono)

- Perseverance (Onipa'a)

- Humility

- Forgiveness (Hui kala)

- Love of God, man, \& land (Lokahi)

- Tolerance

2. I am aware of the different learning styles of the students in my classroom. List different learning styles:
- Experiential (hands-on)
- Visual
- Auditory
- Kinesthetic (music/dance)
- Linear
- Spatial
- Logical
- Gardner's

- Collaborative/cooperative

- Independent

- Role of peers

- Intuitive

- Use of sign language to communicate

- Affective

- Dyslexia

Table 5

Synthesis of Responses Listed to Open-Ended Questions on Values/Beliefs, Learning Styles, and Contrasts (continued) 
3. I am able to compare and contrast my own cultural perspective with another different cultural perspective.

List examples of contrasts:

- Language (standard English vs. pidgin)

- Music (popular vs. chant)

- Customs (shoes in house vs. barefoot)

- Body Language (hugs vs. handshakes)

- Values (spiritual vs. materialistic)

- Sovereignty vs. loss of sovereignty

- Family dominance (matriarchal vs. patriarchal)

- Family make-up (immediate vs. extended)

- Clothing

- Food

- Discipline
- Individualism vs. collectivism ('I' vs. 'us')

- Don't speak out vs. express yourself

- Eastern vs. Western

- Country vs. city

- Eye contact vs. no eye contact

- Time (punctuality vs. island time)

- Process vs. product

- Communication style (questioning vs. listening)

- Self sufficient vs. dependent

- Arts/crafts

- Environment/plants 
Table 6

Synthesis of Responses Listed to Open Ended Questions on Knowledge/Action Orientation of Strategies and Resources (with Pre/Post Frequency Counts listed)

5. I am knowledgeable about instructional strategies for a multicultural classroom. List instructional strategies:

17. I am willing to use instructional strategies to promote respect, understanding, and a sense of belonging for all. List strategies:

- Grouping: teams/cooperative learning groups/learning centers/peers as helpers (21/50),

- Direct instruction/modeling (7/15), vary instructional formats (6/22), differentiated instruction (2/3), individual/lecture (0/2)

- Music, dance, drama, art, community-based projects (9/19)

- Media/computers/visual strategies (reading, writing, pictures) $(7 / 18)$

- Language: use of different languages within content areas, share features in common, sign language (16/16)

- Social justice: sense of equal value; listen, understand, respect, show genuine affection; teach tolerance/community building, use ho'oponopono for conflict resolution (17/17)

- Use community resources; guest speakers, field trips $(8 / 10)$

- Use stories about different cultures (5/7)

6. I am knowledgeable about resources that I might use in a multicultural classroom. List resources:

18. I am willing to use resources/persons from other cultures to promote a global sense of interconnectedness and social responsibility. List resources:

- People: parents/family (15/49), community members/agencies (25/58), kupuna/makua (21/38), other teachers (3/21), guest speakers (8/7)

- Text: books on culture, magazines, newspapers (18/42), curriculum materials (8/21) general \& specific: Ohia Project, E Ola Pono, Voyaging, library (6/6)

- Media: computers/internet (22/27), videos, songs, music (16/21), interactive CD's (4/8),

- Other: English Language Learner (ELL) staff (2/2), students themselves (1/2) 
Multicultural Learning and Teaching (2009), 4(2), 1-24

Figure 1

Pre/Post Gains on the MAP by School Personnel
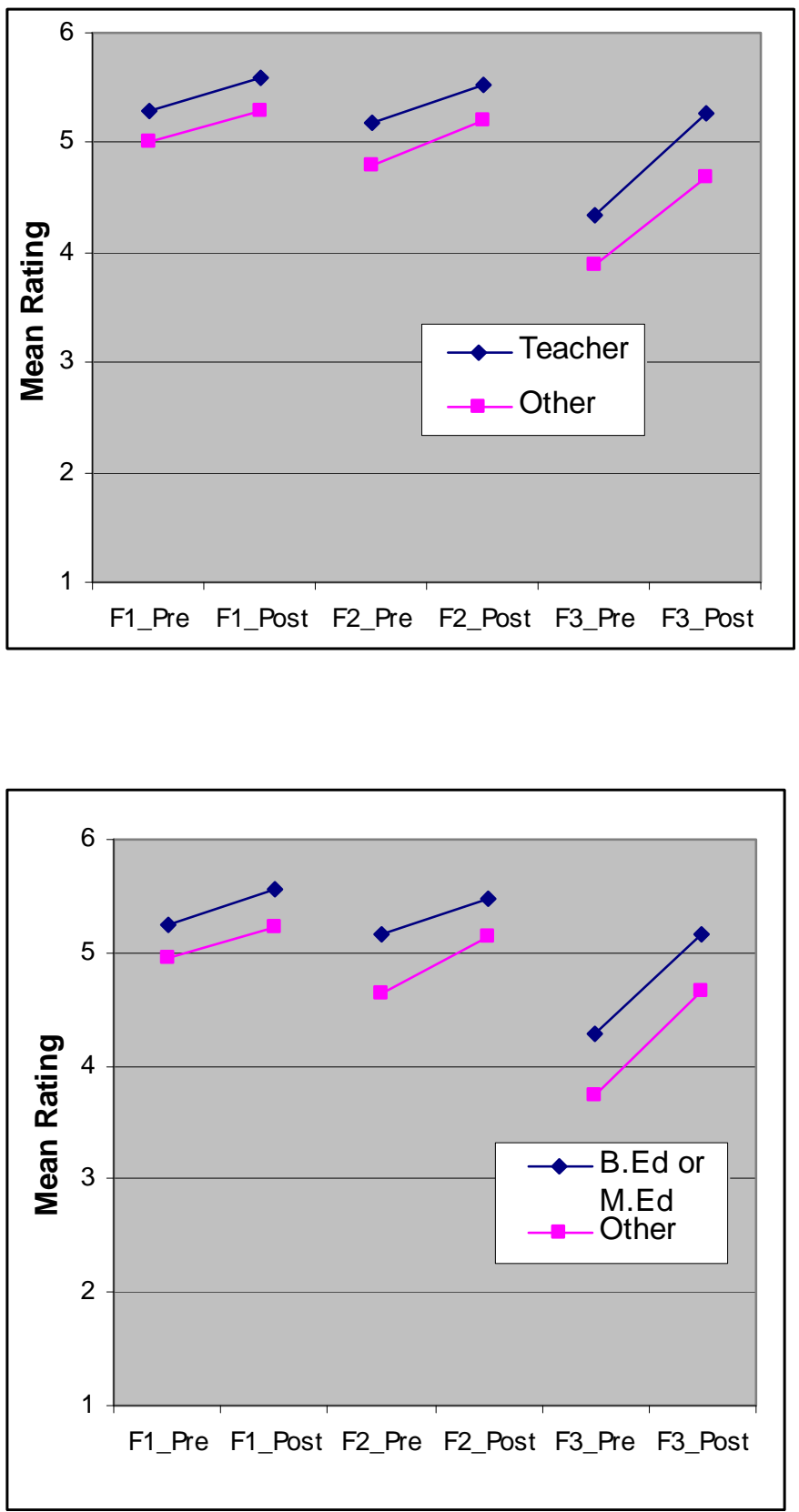

Factor 1: Action Orientation

Factor 2: Awareness

Factor 3: Knowledge

copyright@2001 ch hitchcock 
Multicultural Assessment of Proficiency (The MAP for Teachers) Charting the Voyage Towards Multicultural Proficiency

Questionnaire directions: For each of the following statements, please circle the number that best describes how you would rate the following statements. Use the following codes:

1= Completely Disagree 2= Strongly Disagree 3= Disagree 4= Agree 5 = Strongly Agree 6= Completely Agree

1. I can identify behaviors and attitudes of my

$\begin{array}{cccccc}\text { CD } & \text { SD } & \text { D } & \text { A } & \text { SA } & \text { CA } \\ 1 & 2 & 3 & 4 & 5 & 6\end{array}$

own that are unique to my culture.

List some values/beliefs that are

important to you:

2. I recognize that the concepts of family, community, etc., are different for various

cultures and even for subgroups within

cultures.

3. I am aware of the different learning

styles of the students in my classroom.

List different learning

styles:

4. I am able to compare and contrast my own cultural perspective with another different

1

1

2

3

4

5

6 cultural perspective.

List examples of contrasts:

5. I am knowledgeable about instructional strategies for a multicultural classroom.

$\begin{array}{lllll}2 & 3 & 4 & 5 & 6\end{array}$

List instructional strategies you might

use:

copyright@2001 ch hitchcock 
6. I am knowledgeable about resources that I might use in a multicultural classroom.

List resources that you might

use:

$\begin{array}{llllcc}\text { CD } & \text { SD } & \text { D } & \text { A } & \text { SA } & \text { CA } \\ 1 & 2 & 3 & 4 & 5 & 6\end{array}$

$\begin{array}{lllll}2 & 3 & 4 & 5 & 6\end{array}$
shaping my behaviors, values, and institutions (e.g., family).

8. I am comfortable around people whose cultural backgrounds and values may be different from mine.

9. I believe that diversity within cultures is as important as diversity between cultures.

10. I recognize that the thought patterns of nonAmerican peoples, though different, are equally valid and influence how students view problems and solutions.

11. I feel that it is important to identify resources, strengths and common values between other cultures and my own.

12. I feel that it is important to use a variety of strategies when teaching students from diverse cultures (with diverse learning styles).

13. The first step to becoming an effective teacher in a multicultural classroom is an understanding of my own cultural, ethnic and linguistic background.

14. The ultimate goal of the culturally competent teacher is to recognize and dissolve political and societal barriers that artificially separate us. $\begin{array}{llllll}1 & 2 & 3 & 4 & 5 & 6\end{array}$

$\begin{array}{llllll}1 & 2 & 3 & 4 & 5 & 6\end{array}$

$\begin{array}{llllll}1 & 2 & 3 & 4 & 5 & 6\end{array}$

$\begin{array}{llllll}1 & 2 & 3 & 4 & 5 & 6\end{array}$

$\begin{array}{llllll}1 & 2 & 3 & 4 & 5 & 6\end{array}$

$\begin{array}{llllll}1 & 2 & 3 & 4 & 5 & 6\end{array}$

$\begin{array}{llllll}1 & 2 & 3 & 4 & 5 & 6\end{array}$


15. I am interested in learning (willing to learn) about cultures different from my own.

16. I am willing to use my knowledge about the behaviors, values, and learning styles of students from cultures different from my own to promote learning in my classroom.

17. I am willing to use instructional strategies to promote respect, understanding, and a sense of belonging for all.

List strategies you will use:

$\begin{array}{llllcc}\text { CD } & \text { SD } & \text { D } & \text { A } & \text { SA } & \text { CA } \\ 1 & 2 & 3 & 4 & 5 & 6\end{array}$

$\begin{array}{llllll}1 & 2 & 3 & 4 & 5 & 6\end{array}$

$\begin{array}{llllll}1 & 2 & 3 & 4 & 5 & 6\end{array}$

18. I am willing to use resources/persons from other cultures to promote a global sense of interconnectedness and social responsibility.

List resources you will

use:

19. Teachers must strive to acknowledge, study and celebrate the rich multicultural diversity that we find in our classrooms today.

20. Teachers have the responsibility to be aware of their students' cultural backgrounds.
1

$2 \quad 3 \quad 4$

1

$\begin{array}{lllll}2 & 3 & 4 & 5 & 6\end{array}$

1

2

3

4

5

6 
Author Information: Caryl H. Hitchcock is an Assistant Professor at the Center on Disability Studies, College of Education, University of Hawaii at Manoa; Mary Anne Prater is Professor and Chair of the Department of Counseling Psychology and Special Education, Brigham Young University; Chuan Chang is an Assistant Specialist at the Center on Disability Studies, College of Education, University of Hawaii at Manoa.

Acknowledgement: The authors wish to acknowledge Dr. Anthony Marsella, Professor Emeritus, Department of Psychology, University of Hawaii at Manoa, for his inspiration and assistance in the development of this workshop and questionnaire. We are also grateful to the Hawaii State Department of Education for their support in making these workshops available to their schools and personnel. 